\title{
EDUCAÇÃO DE ELITES E A DIMENSÃO DA INTERNACIONALIZAÇÃO EM PORTUGAL
}

\author{
Anne Schippling \\ Iscte - Instituto Universitário de Lisboa, Centro de Investigação e Estudos de Sociologia \\ (CIES-Iscte), Lisboa, Portugal \& FernUniversität in Hagen, Alemanha \\ Pedro Abrantes \\ Universidade Aberta \& Iscte - Instituto Universitário de Lisboa, Centro de Investigação e \\ Estudos de Sociologia (CIES-Iscte), Lisboa, Portugal \\ João Teixeira Lopes \\ Instituto de Sociologia - Universidade do Porto, Porto, Portugal
}

Resumo Perante os atuais processos de um novo capitalismo global, a educação de elites está marcada por transformações que produzem um campo de tensão entre tendências homogeneizadoras e

heterogeneizadoras. A referência ao internacional ganha, nesse cenário, um conteúdo de significado diverso, que o presente artigo procura reconstruir. Partindo de uma caracterização da educação de elites e da

dimensão da internacionalização a nível global e no contexto português, apresentam-se dois estudos de caso em colégios internacionais na região de Lisboa, que correspondem a modalidades diferentes da construção da sua identidade escolar.

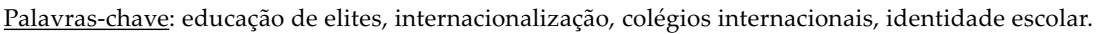

\section{Education of elites and the internationalisation dimension in Portugal}

Abstract Given the current processes of a new global capitalism, the education of elites has been marked by changes that are producing a tension between homogenising and diversifying tendencies. The reference to the international takes on a whole range of meanings that this article seeks to reconstruct. Starting from a study of the education of elites and the internationalisation dimension at both the global level and in the Portuguese context, two case studies will be presented of international schools within the Lisbon region which are adopting different ways of constructing their school identity.

Keywords: education of elites, internationalisation, international schools, school identity.

Éducation des élites et dimension de l'internationalisation au Portugal

Résumé Face aux processus actuels d'un nouveau capitalisme global, l'éducation des élites est marquée par des transformations, qui produisent des tensions entre les tendances homogénéisatrices et les tendances hétérogénéisatrices. Dans ce scénario, la référence à l'international acquiert différentes significations que le présent article cherche à reconstruire. À partir d'une caractérisation de l'éducation des élites et de la dimension de l'internationalisation à l'échelle mondiale et dans le contexte portugais, l'article présente deux études de cas réalisées dans des collèges internationaux situés dans la région de Lisbonne, qui correspondent à des modalités différentes de construction de leur identité scolaire.

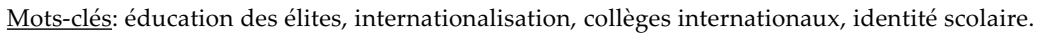

Educación de élites y dimensión de la internacionalización en Portugal

Resumen Ante los actuales procesos de un nuevo capitalismo global, la educación de élites está marcada por transformaciones que producen un campo de tensión entre tendencias homogeneizadoras y

heterogeneizadoras. La referencia a lo internacional adquiere, en ese escenario, un contenido de significado diverso, el cual se procura reconstruir en el presente artículo. Se parte de una caracterización de la educación de élites y de la dimensión de la internacionalización a nivel global y en el contexto portugués para presentar 


\section{Introdução}

Nas últimas décadas, pode constatar-se um movimento transnacional crescente de bens, capitais, informação e pessoas, com consequências também profundas na área da educação (Favell, 2008; Brooks e Waters, 2011; Cairns et al., 2017). No contexto de um novo capitalismo global, em constante mudança, e do crescimento das empresas multinacionais e organizações não governamentais, a procura por trabalhadores globais tem vindo a aumentar. Constata-se a emergência de novas elites globais que respondem a essa demanda, formando- -se em microespaços globalizantes que transpõem as fronteiras nacionais (Sklair, 2001; Sassen, 2005; Wagner, 2007; Costa, 2012; Ball e Nikita, 2014).

O conceito de elite tem origem etimológica no verbo latino eligere, que, em português, significa "escolher", "selecionar", e recebeu diferentes conotações semânticas, durante as várias épocas históricas, sobretudo desde o século XVIII, altura em que foi concebido pela burguesia ambiciosa como um conceito oposto a nobreza e clero (Hartmann, 2004; Louçã, Lopes e Costa, 2014).

Neste artigo, partimos de conceções sociológicas de elite, associadas às teorias da "power elite" (Mills, 1956) ou do "campo de poder" (Bourdieu, 1989), pelo que se recorre igualmente ao conceito de "burguesia" (Louçã, Lopes e Costa, 2014). Com o foco no poder económico, como base da reprodução da estrutura social, o conceito de "burguesia" está estreitamente relacionado com a conceptualização no contexto das teorias críticas de elites. Ao mesmo tempo, procuramos situar o artigo num debate mais recente sobre globalização e internacionalização de elites (ver Maxwell et al. 2018; Hartmann, 2011), contribuindo para responder à seguinte questão: em que medida estes processos "challenge the structures shaping social class formation"? (Deppe et al., 2018: 3).

Partindo da ideia de que a condição humana se tornou cosmopolita (e.g., Beck, 2004) e a formação de redes entre elites que comunicam entre si atravessa o globo e erode as fronteiras nacionais (Castells, 2000; Lauder, 2015), procuramos analisar as implicações desta condição para o campo educativo, no qual as estruturas do estado-nação desempenham ainda um papel central (e.g., Hartmann, 2004; Maxwell et al., 2018).

Durante as últimas décadas, cresceu o número de famílias transnacionais em mobilidade, que Ball e Nikita (2014: 85) caracterizam como uma nova classe de "global mobile professional and managerial workers", que procura uma educação internacional. Pode verificar-se, igualmente, uma tal procura por famílias locais das classes dominantes para proporcionar aos filhos uma melhor 
integração no mercado global de trabalho (Keßler et al., 2015; Resnik, 2016; Naudet, 2012).

Nesse contexto, durante as últimas décadas, observa-se, por um lado, um crescimento exponencial de escolas internacionais a nível mundial, sobretudo no que diz respeito a escolas que são reguladas por organizações educativas transnacionais, como a International Baccalaureate(r) (IB) (IB World Schools) e a Cambridge Assessment International Education (CAIE) (Cambridge Schools); por outro lado, uma diversificação crescente desse campo educativo a nível de currículos e diplomas, conceitos educativos e populações escolares (ver Keßler et al., 2015).

A referência ao internacional tem sido uma estratégia de distinção das elites nacionais (Hartmann, 2004; Vieira, 2003; Maxwell e Aggleton, 2016; Schippling, 2018a), o que se explica pelo facto de o internacional se caracterizar por uma certa indefinição que confere legitimidade a processos de distinção (Waldow, 2018: 251). No entanto, fica em aberto se a internacionalização das elites tem evoluído para um novo patamar, marcado por mudanças na consciência de classe - uma questão até à data muito pouco explorada (ver Lauder, 2015: 179).

\section{A educação de elites em Portugal}

Um estudo recente sobre a burguesia portuguesa (Louçã, Lopes e Costa, 2014), inspirado por um referencial marxista aberto e eclético, permitiu uma análise exploratória sobre os principais modos de relação das famílias burguesas com a socialização escolar, através de uma análise documental de documentos programáticos e websites de algumas das mais consagradas instituições de ensino privado.

Dessa análise ressalta, desde logo, a tensão entre a heterogeneidade e a homogeneidade das classes dominantes, igualmente constatada em França (Pinçon e Pinçon-Charlot, 2007). Por um lado, a oferta educativa nos colégios frequentados por grandes contingentes de herdeiros da burguesia portuguesa é heterogénea, porque heterogénea é também a composição dessa burguesia (ou dessas burguesias, reforçando o plural): alguns colégios oferecem uma educação vincadamente religiosa, outros são assumidamente laicos; certos projetos educativos acentuam a ligação local-nacional, outros apontam para uma formação cosmopolita e uma inserção transnacional; alguns marcam de forma rígida limites e orientações comportamentais, outros fornecem pistas mais fluidas.

Mas há fortes pontos em comum, que poderemos considerar como o "núcleo duro" da educação dos aspirantes da burguesia.

Em primeiro lugar, a forte ligação entre família e escola, numa coligação de forças que tenta, a todo o custo, eliminar dissonâncias no processo de socialização, esforço tão mais necessário quanto a clausura das instituições, por maior que seja, física e/ou simbólica, é hoje atravessada pelas novas lógicas de constituição de sociabilidades, grupos de amigos e influências culturais, cada vez mais ecléticas.

Em segundo lugar, a proliferação de atividades extracurriculares e de tempos livres (algumas mais "simples", como festas, visitas de estudo, passeios, seminários, natação, futebol, ou outro desporto de equipa, outras claramente mais exigentes em 
termos monetários, mas também da aquisição de códigos e disposições para a sua prática, como o ténis, o ballet, o piano, a pintura, a escrita criativa e uma grande insistência, para os rapazes, nas artes marciais, como o caraté e o judo, entre muitas outras), prolongando, desta forma, a ação escolar para outros espaços-tempos, colonizando os lazeres e limitando o orçamento temporal para outras opções eventualmente menos controladas, o que também facilita o trabalho de supervisão familiar.

Em terceiro lugar, a ênfase na "excelência", como critério de distinção e de motivação dos alunos, incorporando a ideia do mérito e do esforço associado ao talento, o que constitui, por um lado, uma "disciplina" (regra, método, calendário de esforço) e uma legitimação do privilégio (são herdeiros, mas devem sobressair no percurso escolar).

Em quarto lugar, o cariz multidimensional da "excelência", medida pelos resultados escolares, antes de mais, mas também pela prossecução de certos valores e condutas, algumas com cunho vincadamente religioso, outras no campo mais vasto da moral, como a assistência social e a compaixão pelos desvalidos.

Em quinto lugar, a tentativa de compromisso possível entre lógicas de "modernidade" (igualdade formal de acesso e sucesso a ambos os sexos; oferta variada de atividades culturais e desportivas), com um tradicionalismo vincado, que vai dos trajes impostos ao condicionamento explícito ou subtil das sociabilidades e dos namoros.

Em sexto lugar, a centralidade da "formação integral", como trabalho pedagógico em várias frentes sobre as identidades, de maneira a garantir a superação de uma mera aquisição superficial de ensinamentos. Importa ir fundo, deixar marcas, obter adesão, criar previsibilidade através de padrões éticos e valorativos duráveis e transferíveis, sob adaptação, de situação para situação.

Assim, estes "novos" herdeiros, filhos de burgueses ou educados a serem aspirantes do mundo burguês, transportarão decerto consigo as diferenças que separam as idiossincrasias individuais, particularmente num tempo que estimula a competição e onde os agentes de socialização são diferenciados e passam mensagens contraditórias. Mas saberão, igualmente, com maior ou menor competência, aguçar o seu sentido de lugar na sociedade, ativando os saberes, os saberes-dizeres e os saberes-fazeres que lhes permitirão sobressair da plebe.

\section{Construções de identidade escolar em dois colégios na área metropolitana de Lisboa}

Perante estas características que determinam a área da educação das elites portuguesas em geral, será analisado em que medida se manifestam as dimensões heterogéneas e homogéneas no que diz respeito à educação internacional e cosmopolita.

Com o campo escolar da educação internacional, procurámos analisar, por um lado, em que medida as elites se (re)produzem através de estratégias educativas que respondem aos desafios de um novo capitalismo global, e, por outro, perspetivar as implicações que a educação internacional e cosmopolita tem na formação de consciência de classe. 
Quadro 1 Fundação das escolas internacionais na AML

\begin{tabular}{|c|c|c|c|c|}
\hline & Antes de 1960 & $\begin{array}{c}\text { Entre } 1960 \\
\text { e } 1980\end{array}$ & $\begin{array}{c}\text { Entre } 1980 \\
\text { e } 2000\end{array}$ & Após 2000 \\
\hline $\begin{array}{c}\text { A) Escolas estrangeiras } \\
\text { tradicionais (propinas: } 5000 \text { euros } \\
\text { a } 7000 \text { euros por ano) })^{1}\end{array}$ & 4 & & 3 & \\
\hline $\begin{array}{l}\text { B) Escolas portuguesas com } \\
\text { currículos internacionais } \\
\text { (propinas: não há indicações } \\
\text { disponíveis) }\end{array}$ & $\begin{array}{c}3 \\
(1 \text { com CAIE } \\
\text { desde 2013) }\end{array}$ & $\begin{array}{c}2 \\
\text { (1 com IB desde } \\
1994 ; 1 \text { com } \\
\text { CAIE desde } \\
2015)\end{array}$ & $\begin{array}{c}1 \\
\text { (com IB desde } \\
2015 \text { e CAIE } \\
\text { desde 2019) }\end{array}$ & 1 \\
\hline $\begin{array}{l}\text { C) Escolas internacionais, em } \\
\text { sentido estrito (propinas: entre } \\
17000 \text { euros e } 22000 \text { euros) }\end{array}$ & $\begin{array}{c}3 \\
\text { (2 com IB desde } \\
\text { 1994; } 1 \text { com IB } \\
\text { desde } 1986 \text { e } \\
\text { CAIE) }\end{array}$ & & $\begin{array}{l}1 \text { (com CAIE } \\
\text { desde 2010) }\end{array}$ & $\begin{array}{c}6 \\
\text { (1 com IB desde } \\
2010 \text { e } 5 \text { com } \\
\text { CAIE desde } \\
2008)\end{array}$ \\
\hline
\end{tabular}

Notas: 1 - A indicação de propinas refere-se ao ensino secundário. No caso destas escolas, são frequentemente tuteladas por Estados estrangeiros que asseguram também uma parte do financiamento; 2 - A data da introdução dos currículos internacionais (IB e CAIE) é indicada quando disponível.

Fonte: Pesquisa de sítios web e documentos de autorrepresentação de escolas internacionais na AML, assim como sítios web de organizações educativas transnacionais.

Na área metropolitana de Lisboa (AML), pode constatar-se um constante crescimento das escolas internacionais, ao longo das últimas décadas (ver quadro 1).

No total, foram identificadas 24 escolas internacionais na AML, nove unicamente com o ensino básico e 15 com ensino básico e secundário. Verifica-se, por um lado, que as escolas internacionais já têm uma longa tradição na formação das elites portuguesas (ver e.g., Vieira, 2003). Por outro lado, nota-se um crescimento constante desse segmento escolar a partir dos anos $80 \mathrm{e}$, mais especificamente, um crescimento do número das escolas internacionais com propinas mais elevadas a partir de 2000. Além disso, pode ser constatada uma influência crescente de organizações educativas transnacionais, como o IB e a CAIE, cujos currículos são adaptados pelas escolas, sobretudo ao longo da última década.

A seguir, vão ser reconstruídas orientações relativas à identidade escolar, ${ }^{1}$ com foco na dimensão do internacional, de diretores e de alunos do $11 .^{\circ}$ ano em colégios internacionais da área metropolitana de Lisboa (AML) (dos grupos A e C). Ao mesmo tempo, será analisado o impacto que essas orientações têm nos processos de construção de identidade cultural e social dos alunos.

Numa perspetiva teórica, o projeto de investigação, ${ }^{2}$ que analisa, pela primeira vez, o campo de colégios internacionais na $A M L$, assenta num conceito integrativo da identidade escolar. Este conceito permite, por um lado, perspetivar o posicionamento da organização no seu ambiente e recorrer a teorias neoinstitucionalistas. Por

1 O conceito de identidade escolar encontra-se desenvolvido e problematizado em Abrantes (2003). 
outro lado, visa entender essa identidade como construção social dos atores e das suas interações (discursivas), sublinhando aqui o "papel ativo" da escola "no processo de construção identitária" (Abrantes, 2003: 17). Desta forma, este conceito integrativo permite analisar a interligação processual das autodefinições dos atores, enquanto membros da organização e o seu ambiente institucional e social (Draelants e Dumay, 2011: 6). O impacto das organizações educativas transnacionais, como a International Baccalaureate (IB) e a Cambridge Assessment International Education (CAIE), representa um elemento fundamental na construção da identidade de alguns colégios internacionais na AML (ver quadro 1). A análise também está ligada ao conceito de habitus de Pierre Bourdieu $(1972,1989)$, desenvolvido numa perspetiva institucional (e.g., Reay, 1998; Schippling 2018a). Para além disso, recorre, numa perspetiva de ultrapassar o nacionalismo metodológico, que pressupõe uma identidade entre sociedade e estado-nação (e.g., Beck, 2007), a conceitos da investigação sobre transnacionalidade, aplicados no campo escolar, como, por exemplo, o conceito de "espaço transnacional de educação" (e.g., Adick, 2005; Hayden, 2011; Schippling, 2018b): um conceito que se caracteriza por uma grande intensidade de interligações transfronteiriças ao nível das práticas (discursivas) dos atores sociais.

No que diz respeito ao design da investigação, tendo por base um estudo exploratório que permitia uma visão geral do campo de colégios internacionais na AML, foram realizados estudos de caso aprofundados, cuja seleção se baseava nos resultados do estudo exploratório (ver Schippling e Abrantes, 2018). Os estudos de caso abrangem entrevistas semidiretivas com diretores e administradores de escola, grupos focais com alunos e professores, observação participante em eventos culturais das escolas, bem como análise de sítios web e outros documentos de autorrepresentação das escolas.

A análise desses dados baseia-se no documentary interpretation method, inicialmente elaborado por Ralf Bohnsack, um método reconstrutivo da investigação qualitativa adequado para analisar dados empíricos qualitativos de natureza variada, como, por exemplo, grupos focais (Bohnsack, Pfaff e Weller, 2010) ou entrevistas (Nohl, 2006). O método recorre, sobretudo, a elementos da teoria do conhecimento de Karl Mannheim e à tradição da etnometodologia e visa, em primeiro lugar, a reconstrução de um conhecimento implícito ou "ateórico", subjacente à ação social habitual (Bohnsack, Pfaff e Weller, 2010: 110-111).

Foram selecionados dois colégios que correspondem, devido ao contexto histórico e cultural onde surgiram, a modalidades diferentes da construção de uma identidade enquanto "colégio internacional". Primeiramente, será elaborada, relativamente a cada estudo de caso, uma caracterização geral da respetiva escola, tendo como base os resultados de uma análise de sítios web e uma entrevista semidiretiva com o diretor da escola. Segue-se uma apresentação de resultados da

2 Os resultados da investigação que a seguir vão ser apresentados baseiam-se num projeto de pós-doutoramento, intitulado "A Internacionalização da Educação das Elites em Portugal. Um Estudo Qualitativo sobre Colégios Internacionais na Grande Lisboa" (CIES-IUL, Lisboa; Universidade Martin-Luther, Halle-Wittenberg), que é financiado pela Fundação para a Ciência e a Tecnologia (FCT) (SFRH/BPD/112406/2015 - início do projeto: 01/01/2016). 
análise de focus groups com alunos do $11 . \stackrel{\circ}{ }$ ano (escola A: 3 focus groups; escola B: 4 focus groups).

\section{Escola A - escola com currículo estrangeiro}

\section{Caracterização geral da escola A e orientações do diretor}

A escola A é uma escola internacional que oferece exclusivamente currículos e diplomas estrangeiros, sob a tutela do respetivo Ministério da Educação nacional. Este colégio engloba todos os níveis escolares, do primário ao secundário, e faz parte de uma rede desse tipo de escolas no estrangeiro. Em termos de regulação, é financiado parcialmente pelo estado estrangeiro, não é autónomo e, por isso, não pode ser entendido como um colégio completamente privado.

Na homepage da escola aparece o seguinte relativamente à sua missão:

Ela tem como objetivo assegurar, a favor das crianças da nacionalidade [nacionalidade estrangeira de origem da escola] residentes em Portugal, e mais particularmente em Lisboa, as missões do serviço público relativamente à educação (programas e diplomas conforme as diretivas do Ministério da Educação nacional). Ela deve, além disso, contribuir para a receção de alunos portugueses e outros estrangeiros, para a difusão da língua e cultura [nacionalidade estrangeira de origem da escola]. ${ }^{3}$ (website da escola A)

Salienta-se que o enfoque numa cultura e língua específicas domina o discurso do diretor. Para além disso, na construção da identidade escolar, manifesta-se uma orientação de dualidade entre os referenciais "nacional" e "estrangeiro". Ele designa como "o cartão de identidade" da sua escola, e das outras escolas que fazem parte desta rede global, o ensino segundo o currículo do sistema público nacional estrangeiro, aplicando a metodologia de ensino e aprendizagem do país de origem, em combinação com uma grande oferta de ensino de línguas vivas.

Nesse sentido, segundo o diretor, o objetivo fundamental da escola consiste em fornecer competências aos alunos de modo a que estes sigam um percurso marcado pela "mobilidade internacional", que se dirija particularmente à do país de origem da escola:

A ideia é mesmo que como adquiram um certo, vamos dizer um certo espírito de tolerância e de abertura, que eles dominem várias línguas vivas, isto é, de incentivar os alunos a seguir os seus estudos no estrangeiro, obviamente em direção à [país de origem da escola] [entrevista com o diretor da escola A].

3 Algumas entrevistas e grupos focais foram realizados na língua de origem das escolas. Por razões de anonimato, foram traduzidos para a língua portuguesa. Anne Schippling e Ricardo Cabrita são responsáveis pelas respetivas traduções. A tradução e revisão deste artigo foi financiada pela Fundação para a Ciência e a Tecnologia através do Strategic Financing da R\&D Unit (UID/SOC/03126/2013). 
Para assegurar os estudos superiores dos alunos, em universidades prestigiadas a nível mundial, o diretor considera fundamental promover o "sucesso nos exames [nacionalidade do país de origem da escola]". Nesse âmbito, ele considera que a sua escola dá "uma formação de excelência", onde se manifesta uma das dimensões da educação das elites portuguesas identificadas em trabalhos anteriores (e.g., Louçã, Lopes e Costa, 2014).

\section{Orientações de alunos da escola $A$}

Uma primeira orientação, que marca os discursos dos alunos, oriundos de famílias portuguesas, residentes em Lisboa, uma população forte nessa escola, é o enfoque nas famílias e na tradição familiar: uma outra característica da educação das elites portuguesas. Essa orientação desempenha um papel central na escolha do estabelecimento de ensino.

[...] eu sou de Lisboa, sou de cá, sempre vivi cá, eu vim [para a escola A], porque a minha mãe sempre estudou [em escolas $\mathrm{A}$ ], mas à volta do mundo, porque o meu avô era embaixador de Portugal [focus group com os alunos da escola A].

A referência ao internacional decorre, no caso desta aluna, da tradição da sua família, que tem tido uma relação com o estrangeiro durante mais de duas gerações. Trata-se, portanto, de uma história marcada pela mobilidade, que surgiu por causa da posição profissional do avô.

A escolha da escola surge das ideias dos pais e é legitimada pela tradição familiar, aparecendo aqui como um processo inquestionável, de certo modo naturalizado: "não havia outra hipótese sem ser mesmo [a escola A]".

A dimensão internacional, no que diz respeito à escolha da escola, aparece aqui como fator da preservação da reprodução social de famílias autóctones. A orientação baseada na tradição da família está ligada, igualmente, a um conhecimento profundo sobre a tradição da escola, tendo em conta o seu papel durante a ditadura portuguesa, e das figuras ilustres que a frequentaram.

As orientações da escolha escolar estão em estreita relação com a construção da identidade social e cultural dos alunos. Com base na referência a uma argumentação meritocrática, que se manifesta também no discurso do diretor da escola, os estudantes portugueses autoidentificam-se como uma futura "elite intelectual". Essa identificação vai ao encontro da tradição escolar, sendo a escola entendida como um lugar de formação de pessoas ilustres, e os alunos, dessa maneira, procuram enfatizar a ideia de "excelência" da educação da sua instituição:

[...] de certa forma, são pessoas que vão acabar [...] por ser uma elite, não é? [...] [não vamos] ser os mais ricos, mas uma elite intelectual [focus group com os alunos da escola A].

A identificação com uma futura "elite intelectual", que funciona como horizonte positivo, relaciona-se com a distinção face a uma "elite económica". Tanto os alunos portugueses como os alunos estrangeiros se distanciam da caracterização feita 
por pessoas externas à escola, sendo esta vista como uma instituição para uma elite económica ("escola de pessoas mais ricas, pronto"). Para eles, essa ideia não passa de um "clichê". Para fundamentar a argumentação meritocrática, nesse caso, no que diz respeito ao acesso à escola, os estudantes assinalam que a escola também recebe os filhos dos seus empregados, que não podem pagar as propinas.

No entanto, também há vozes críticas entre os alunos. Um grupo da nacionalidade estrangeira de origem da escola refere que esta está socialmente fechada, sobretudo para a população portuguesa, porque as propinas, para os portugueses com salários comparativamente mais baixos ("os expatriados ganham melhor"), seriam demasiado elevadas. Além disso, também haveria mais bolsas para os alunos (da respetiva nacionalidade estrangeira) do que para os estudantes portugueses.

No que diz respeito ao conceito de "internacional", os alunos associam, por um lado, a possibilidade oferecida pela escola de aprender diferentes línguas, por outro, apreciam o encontro com diferentes culturas na escola. Eles, na linha do diretor, consideram sobretudo a aquisição de diferentes línguas como sendo vantajosa para o seu futuro académico e profissional.

No primeiro plano da identificação cultural dos alunos, encontra-se, de acordo com o discurso do diretor, a dualidade entre o país de origem da escola e Portugal, que está a ser abordada em diferentes contextos. Para além disso, os estudantes da nacionalidade estrangeira do país de origem da escola identificam uma dominância da sua cultura no colégio e presumem que os alunos portugueses "se sentem um pouco esmagados por isso tudo" [focus group com os alunos da escola A].

Dentro da lógica da dualidade cultural, nos discursos dos alunos portugueses, verifica-se uma distinção clara da escola em relação às escolas públicas portuguesas: "nós [...] fazemos um trabalho muito melhor que eles, pela simples razão que nós estamos habituados a ter muito mais trabalho do que eles" [focus group com os alunos da escola A]. Aparece aqui, novamente, a figura de distinção de natureza meritocrática, que está relacionada com a legitimação do estatuto social dos alunos.

\section{Escola B - escola com currículo internacional (IB)}

\section{Caracterização geral da escola B e orientações do diretor}

A escola B é um colégio privado que oferece exclusivamente os programas do International Baccalaureate, do ensino básico até ao secundário, sendo regulada pela organização IB e outras organizações educativas transnacionais, como a ECIS (European Council of International Schools) ou a NEASK (New England Association of Schools and Colleges).

A sua missão é a seguinte:

A missão da [escola B] é nutrir as pessoas e cultivar uma mentalidade internacional e um sentimento de cidadania global, oferecendo uma formação internacional de qualidade que promove características intelectuais, sociais, físicas, emocionais, morais e espirituais únicas, que são inerentes a todas as pessoas [website da escola B]. 
Essa orientação para uma "formação integral", que igualmente foi identificada em estudos anteriores sobre a educação das elites portuguesas (ver e.g., Louçã, Lopes e Costa, 2014; Abrantes e Quaresma, 2013; Quaresma, 2014), também se evidenciou na entrevista com o diretor da escola, para quem a educação engloba mais do que só o aspeto académico, identificando a escola, nesse contexto, como "escola inclusiva". Ele constrói a identidade escolar com base no distanciamento de uma "escola seletiva, que, essencialmente, só vai aceitar alunos que achem que vão ter bons resultados nos exames" [entrevista com o diretor da escola B]. A escola seletiva, conceito através do qual o diretor identifica outras escolas (internacionais) na região, aparece como horizonte negativo, do qual ele diferencia a sua instituição, afastando-se dessa forma de uma orientação para a "excelência", pelo menos no que diz respeito à dimensão académica.

O diretor relaciona a orientação para a inclusão com a ideia de educação para "mentalidade internacional" e um "sentimento de cidadania global", que aparecem no mission statement como primeiras finalidades da escola. A existência de uma vasta panóplia de culturas e línguas diferentes na escola, que o diretor comprova com uma indicação quantitativa, constitui uma base de legitimação de que se trata de uma escola inclusiva:

[...] temos cerca de 600 alunos, desde o infantário até ao 12.ํano, temos, na última contagem, 43 nacionalidades dentro da escola, e essas, dentro dessas 43 nacionalidades, há 25 línguas maternas [entrevista com o diretor da escola B].

A orientação para a dualidade entre dois contextos nacionais, que marcava as construções da identidade escolar dos membros da escola A, na entrevista com o diretor da escola B, aparece diluída. O dirigente faz referência a muitos contextos culturais e linguísticos. No entanto, essa referência traduz-se numa indicação quantitativa e não numa caracterização de situações e práticas concretas da vida escolar.

O discurso da inclusão, que o diretor fundamenta com dados quantitativos sobre as diferentes nacionalidades e línguas presentes no colégio, pode ser entendido como uma forma de ocultar que a escola, tendo em conta as altas propinas, é marcada à partida por processos de seletividade social (ver também Schippling e Abrantes, 2018).

Outra referência fundamental que caracteriza as afirmações do diretor da escola B, em termos da construção da identidade escolar, é a vinculação à organização educativa transnacional International Baccalaureate. $O$ facto de o estabelecimento de ensino fornecer o currículo e diplomas internacionais IB e se orientar pelo IB learner profile, segundo o diretor, oferece a garantia de se tratar de uma escola internacional.

Tal como o diretor da escola A, este dirigente também procura preparar os alunos para o futuro, mas, neste caso, não fazendo referência a um contexto estrangeiro específico, mas sim ao "mundo cada vez mais interligado e inter-relacionado". Neste contexto, segundo o diretor, o colégio tenta responder às necessidades de uma sociedade em transformação através de processos de globalização com uma oferta educativa para "o que os pais querem para os alunos", sublinhando dessa forma o papel dos pais na escolha da escola. A finalidade educativa visa, por um lado, a integração 
dos alunos, para que eles possam "ocupar o seu lugar" na sociedade globalizada, por outro, o respeito pelas suas origens culturais.

\section{Orientações de alunos da escola B}

A maioria dos alunos da escola B tem uma biografia marcada por mobilidade internacional e consequente mudança de escola, sendo oriundos de famílias transnacionais e móveis, em muitos casos a trabalhar para grandes empresas multinacionais. Estas famílias procuram a escola B porque, por um lado, facilita a integração dos estudantes, provenientes de diferentes sistemas escolares, no sistema internacional e, por outro, a língua de ensino é o inglês. As razões para a escolha desta escola são mais pragmáticas do que baseadas numa forte identificação com este estabelecimento de ensino em particular, como aconteceu no exemplo dos alunos portugueses da escola A. Para muitos deles, a escola B nem sequer teria sido a sua primeira escolha:

Então, viemos cá para Portugal e, no início deste ano letivo e estivemos a ver escolas diferentes que falassem inglês e as únicas duas que encontrámos foram a [escola X] e a [escola B] e a [escola B] foi a que me aceitou. É por isso que cá estou [focus group com os alunos da escola B].

Aquando do primeiro contacto, estes alunos experienciam a situação como "mesmo muito confortável" e de fácil acesso: "não são muito rígidos no processo de admissão, portanto". Este argumento corresponde ao discurso do diretor que caracteriza a sua instituição como "escola inclusiva", que se diferencia de uma "escola seletiva" que seleciona e avalia os alunos exclusivamente com base no sucesso académico, manifestando-se, dessa forma, também ao nível dos alunos, um distanciamento da ideia de "excelência académica".

A escola, nas construções dos alunos, aparece como um lugar "muito relaxado", onde os professores os apoiam para se desenvolverem enquanto pessoas e adquirirem independência "[...] e tentam fazer com que decidamos as nossas coisas, [de forma] muito mais independente, mas também tentam fazer com que cresçamos enquanto pessoas" [focus group com os alunos da escola B].

Em contraste com os alunos da escola A, que sublinharam a quantidade de trabalho como característica distintiva de outras escolas, os alunos da escola B, em sintonia com o diretor, salientam a valorização de uma educação integral da pessoa, que ultrapassa a mera dimensão académica.

Nessa construção discursiva, está ausente a figura argumentativa de meritocracia. No entanto, o colégio é descrito como um lugar "descontraído". Essa construção funciona como horizonte positivo. A construção da identidade da escola, utilizando essa imagem, pode ser interpretada, na linha de Bourdieu $(1979,1989)$, como a manifestação de um habitus das elites, marcado por uma relação descontraída e até diletante com o sistema educativo.

Em relação à construção da ideia do internacional, como elemento da identidade escolar, o horizonte positivo da "escola inclusiva", que caracterizava a construção da identidade escolar pelo diretor, também se manifesta no discurso dos alunos. 
Eles experienciam o internacional na sua escola, no encontro de várias culturas quotidianamente, o que determina o seu dia a dia escolar:

Como todos os alunos, todos os professores, nós somos, todos nós temos diferentes historiais, todos estivemos em sítios diferentes, e acho que é isso que sustenta a ideia de sermos todos unidos e nos tentarmos ajudar, porque [nomes de alunos] se calhar não sabe uma coisa, mas ele podia ensinar-lhe que é a forma como nos ajudamos, a coisa internacional [focus group com os alunos da escola B].

O facto de tanto os alunos como os professores serem oriundos de diferentes contextos culturais é apresentado como um valor formativo acrescentado e um fator de coesão interna ("a ideia de sermos todos unidos"). A expressão "nos tentarmos ajudar" é repetida e diretamente associada ao "a coisa internacional". O internacional é introduzido através de uma descrição prática de como os membros da escola se entreajudam e de como ensinam uns aos outros elementos dos seus diferentes contextos culturais, sem hierarquizar um contexto nacional específico. Nessas construções discursivas, a ideia do internacional é tida como inerente às micropráticas da vida escolar. Durante a observação participante, também se manifestaram em eventos da cultura escolar, como, por exemplo, o evento do International Day, onde foi organizado um encontro das diferentes culturas presentes na escola. Aqui, as famílias dos diferentes países preparavam bancas com comidas e artefactos típicos - práticas ligadas a uma ideia do internacional. Questiona-se, no entanto, se através destas práticas foram constituídos espaços transnacionais de educação, marcados por interligações transfronteiriças densas, ou se estas práticas culturais se movimentam mais a um nível que Roman (2003: 276) chama "citizen-consumers in a global marketplace in which cultural practices are mere commodities".

Há também vozes críticas entre os alunos no que diz respeito à dimensão da internacionalidade. Admitindo a existência de várias culturas diferentes na escola, alguns estudantes afirmam que a identidade dessa instituição está marcada, sobretudo, por uma referência ao Reino Unido, principalmente no que diz respeito à orientação institucional relativamente à escolha do futuro percurso académico e profissional: "querem que vamos para um país onde se fale inglês" [focus group com os alunos da escola B].

A autorrepresentação como "escola inclusiva", que valoriza todas as culturas sem privilegiar nenhuma, é, assim, posta em causa, sendo igualmente questionada a construção discursiva da escola como "escola inclusiva" defendida pelo diretor com a função de ocultar que o acesso à escola é marcado por processos de seleção social.

Tal como no caso dos alunos da escola A, existe também uma consciência desses alunos de que a ideia de "escola inclusiva" é abalada porque há uma barreira económica no acesso à escola:

Aluno 1: É verdade, esta escola é mais cara do que a maioria das escolas em Portugal, mas não, não parece nada ser assim [elitista]. Eu não...

Aluno 1: Não é... 
Aluno 2: Eles não agem como se fossem...

Aluno 1: Elitistas, pois [focus group com os alunos da escola B].

Ao mesmo tempo, existe entre eles um distanciamento relativo à construção da escola como escola de elite, mas através de elaborações argumentativas distintas das utilizadas pelos alunos da escola A (com referência ao discurso meritocrático). Assim, os alunos da escola B associam ao conceito de elite a um sentimento de superioridade ("elitista"), do qual se distanciam. Tendo como horizonte de referência alunos de outras escolas internacionais, que consideram ter um comportamento "chique" ou "queque", nesse contexto, delineiam o seu colégio como "mais relaxado do que as outras escolas são", recorrendo, dessa forma, a uma construção discursiva de uma abordagem descontraída e até diletante, no que diz respeito a aspetos educativos.

\section{Síntese e discussão}

Numa visão global, observam-se algumas semelhanças ao nível da construção da identidade escolar entre ambas as escolas: por um lado, a preservação de um público maioritariamente muito favorecido em termos socioeconómicos, embora com a recusa do conceito de "elite" (pelo menos, na vertente económica) e alguma preocupação com a inclusão; por outro lado, a ostentação de um público assaz diversificado em termos de origens culturais e geográficas. Aliás, esta característica fundamenta e facilita a afirmação de projetos educativos que, em ambos os casos, procuram distinguir-se face a um ensino massificado (nomeadamente, público, mas também algum privado) com ênfase nas mais-valias de uma experiência/formação alargada, em termos de competências e, sobretudo, de dimensão internacional, consubstanciada no conhecimento de várias línguas e culturas. ${ }^{4}$

Notam-se, em ambos os colégios, divergências entre as construções dos diretores e dos alunos. Há, por exemplo, vozes de alunos que colocam em causa a imagem institucional da escola B, enquanto um lugar determinado por "mentalidade internacional", no sentido de que orienta os alunos, no que diz respeito ao seu futuro percurso académico e profissional, para o Reino Unido e para a língua inglesa, enquanto no caso da escola A existe a crítica de um certo fechamento na cultura e instituições do país de origem, o que acaba também por condicionar os projetos dos seus estudantes.

Contudo, as construções da identidade escolar, com foco na dimensão do internacional, variam a vários níveis. Além de se manifestarem diferenças no que diz respeito à representação institucional de cada colégio, também se nota variedade, sobretudo entre as construções da identidade escolar pelos diretores em confronto

4 É uma perspetiva de investigação fecunda poder analisar de que forma a referência ao internacional se manifesta em outros campos escolares, como, por exemplo, no campo do ensino público, e refletir sobre as razões dos diferentes discursos relativos ao internacional, em diferentes campos, numa perspetiva comparativa. 
com os alunos. Ao nível das orientações dos alunos, não só se verificam diferenças entre as duas escolas, mas também uma assinalável heterogeneidade no interior de cada uma delas.

Relativamente à apresentação institucional dos websites, mas também às entrevistas com a direção, opõe-se uma construção que se baseia na ênfase do ponto de referência de uma nação e cultura estrangeiras específicas (escola A) a uma construção de uma "escola inclusiva", marcada pela "mentalidade internacional", aberta a todas as nacionalidades, sem qualquer privilégio (escola B). Baseando-se nessa orientação de inclusão, o diretor distingue a sua escola de uma "escola seletiva", que, segundo ele, é uma escola que se limita unicamente à dimensão académica e que não valoriza uma educação holística que abarca o indivíduo em todas as suas dimensões. Ao mesmo tempo, essa recorrência à inclusão serve para ocultar que a escola pode ser identificada como "escola exclusiva" no que diz respeito à seleção social do seu acesso, nomeadamente pelo valor das propinas.

O ponto de referência para a escola $\mathrm{A}$, tanto na sua apresentação oficial como na entrevista com o diretor, em contrapartida, consiste nas exigências do sistema público nacional do país estrangeiro de origem da escola, construindo, dessa forma, no que diz respeito à dimensão internacional, uma figura de dualidade (país estrangeiro/Portugal). Ao contrário do diretor da escola B, o diretor da escola A valoriza intensamente a dimensão académica e o sucesso escolar dos estudantes, identificando o seu colégio como um lugar de formação para a excelência, construindo, assim, um discurso meritocrático de legitimação.

No que diz respeito aos alunos da escola $\mathrm{A}$, a dualidade das referências nacionais também determina a construção da identidade escolar, ideia igualmente partilhada pelo diretor dessa escola. Assim, fazem uma clara distinção em relação às escolas públicas portuguesas, que funcionam, nesse caso, como horizonte negativo. Recorrendo a um discurso de natureza meritocrática, tal como o diretor, o grupo entrevistado de alunos portugueses da escola A legitima essa distinção, tendo em conta a maior quantidade e a qualidade do trabalho comparativamente a outros estabelecimentos de ensino portugueses, situando-se na imagem da escola como lugar de formação para a excelência. Em contraste, os estudantes da escola B descrevem o seu colégio como um lugar "descontraído", que possibilita a entreajuda de pessoas que se unem pelo facto de que são todas, alunos e professores, oriundas de diferentes contextos culturais. Esta construção discursiva pode ser interpretada segundo a linha teórica de habitus das elites que legitimam assim a sua posição privilegiada (ver Bourdieu, 1979, 1989), correspondendo à do diretor, que apresentou a escola como "escola inclusiva". Refira-se, aliás, que este projeto refletirá uma fase mais avançada do capitalismo tardio, no qual se espera que as empresas - pelo menos, as que servem os nichos mais privilegiados - providenciem soluções flexíveis e personalizadas ("customized"), valorizando precisamente trabalhadores criativos e capazes de trabalhar em rede ("soft skills") (ver e.g., Boltanski e Chiapello, 1999).

Em síntese, verifica-se uma imagem complexa e heterogénea relativamente à construção da identidade no exemplo de dois estudos de caso de colégios internacionais na região de Lisboa, o que pode ser uma manifestação de disposições variadas dos membros das escolas enquanto construção da classe social. Enquanto a 
população de famílias residenciais portuguesas (parte da população da escola A) tende a reproduzir a tradição familiar através da referência ao internacional, vinculando-se especificamente a um país estrangeiro de referência no sistema-mundo (ver também Vieira, 2003; Macedo, 2009; Louçã, Lopes e Costa, 2014; Macedo e Araújo, 2016), os alunos de famílias globalmente móveis (parte da população da escola A e escola B) têm uma abordagem diferente, no que diz respeito ao internacional. A escola, para eles, surge, por um lado, ao nível das micropráticas dos membros escolares, como um lugar de encontro e entreajuda entre várias culturas; e, por outro, ao nível dos currículos e práticas institucionais, como um lugar marcado por relações hegemónicas entre culturas e línguas presentes na escola.

No que diz respeito ao "núcleo duro" de aspetos homogéneos da educação das elites, identificados em trabalhos anteriores (e.g., Louçã, Lopes e Costa, 2014), verifica-se, nas duas escolas, a orientação para uma formação integral; no entanto, as escolas diferenciam-se, por exemplo, no papel da família na educação ou na ênfase na excelência, sendo a escola A mais marcada pelos aspetos homogéneos, anteriormente identificados, da educação das elites.

\section{Conclusão e perspetivas}

O presente estudo procurou contribuir para o conhecimento e a discussão sobre a educação das elites, no Portugal contemporâneo, partindo de um filão de estudos sociológicos anteriores sobre o tema e discutindo-o em diálogo com um estudo em curso sobre as escolas internacionais. Nos estudos anteriores, estas escolas tinham ainda uma expressão secundária, mas esta é uma situação que se encontra em transformação acelerada, tendo em conta a expansão que se tem observado das escolas internacionais, em Portugal e por todo o mundo. É certo que nem todas estas escolas se orientam para uma educação de elites, mas a análise preliminar dos custos obrigatórios para as famílias e de outros critérios de acesso permitiu delimitar claramente um conjunto crescente de escolas com estas características na região de Lisboa.

Ao alargar a pesquisa ao âmbito das escolas internacionais, poderá definir-se este como um "nicho" específico e em expansão para a educação das elites, sendo possível relativizar alguns dos elementos de homogeneidade observados em estudos anteriores mais focados em segmentos tradicionais das elites (e.g., Louçã, Lopes e Costa, 2014). Por um lado, tal ocorre no contexto do aprofundamento do capitalismo global, no qual as elites tendem a coaptar novos membros e a adotar diferentes estratégias de reprodução, acumulação e conversão dos seus capitais, nomeadamente no quadro de trajetórias intergeracionais, perante um futuro que a larga maioria tende a reconhecer como incerto e problemático. Por outro lado, poderá inclusive situar-se a heterogeneidade observada no quadro de uma crescente crítica às elites económicas que vai povoando o discurso público e que motiva novas solidariedades e algumas demarcações ou encobrimentos - subtis, nuns casos através da afirmação de uma superioridade cultural e moral (mais aceite no espaço público) que desvaloriza (e justifica) os privilégios económicos, e noutros casos através de um investimento na formação de redes 
sociais e de disposições, de índole distintiva e cosmopolita, que poderão criar mais-valias na adequação às novas solicitações e dinâmicas do capitalismo global, inclusive relativamente às atuais gerações no ativo, contornando as aculturações e filiações que têm por referência estados nacionais concretos.

Em qualquer dos casos, não deixa de ser evidente, não apenas que a educação continua a constituir um campo fundamental de investimento das elites, no âmbito das suas estratégias intergeracionais de reprodução e acumulação, mas também que tais desígnios, apesar de algumas variantes, continuam a passar por uma certa "reclusão" das novas gerações em ambientes exclusivos em termos de classe, bem como claramente distintivos, em termos curriculares, culturais e organizacionais face aos referentes normativos que regulam as escolas frequentadas pelas demais classes sociais, no sentido de propiciar um modelo de socialização total, no qual a incorporação de determinados valores e disposições (o "saber-ser" e o "saber-estar") é tão ou mais importante que a aquisição de conhecimentos.

Por fim, tratando-se de uma pesquisa de carácter exploratório, abre caminho a novas indagações que se pretendem explorar em futuros projetos. Uma questão que importa aprofundar é o carácter biográfico das análises, numa perspetiva longitudinal, procurando compreender como a escolarização em estabelecimentos internacionais se reflete em trajetórias mais alargadas, no ensino superior, no mercado de trabalho e no próprio espaço social, particularmente na relação entre dinâmicas locais, nacionais e globais que se entretecem nesses diferentes contextos. Pesquisas recentes, por exemplo, sobre os jovens recém-ingressados em nichos laborais privilegiados e em expansão, como é o caso do direito financeiro (Santos, 2018), têm mostrado que a valorização de experiências, redes e disposições cosmopolitas não é contraditória com a preferência que continua a ser dada à frequência e diploma de certas instituições do ensino superior que mantêm uma matriz claramente associada ao estado-nação. Outra linha de investigação que importará aprofundar é, precisamente, o que há de comum e de específico sobre esta relação entre a educação internacional e a formação das elites, em Portugal, em comparação com outros países e tendo em conta a trajetória de Portugal no xadrez do capitalismo global. Sem esquecer que também Portugal está a investir na criação de escolas internacionais portuguesas, o crescimento de um modelo globalmente hegemónico, com fortes raízes anglo-saxónicas, não deixa de promover o país como um local de passagem de elites globais e mesmo de aprofundamento da constituição de uma elite global com níveis de concentração de poder inéditos e uma relação muito escassa com os normativos e filiações nacionais.

\section{Referências bibliográficas}

Abrantes, Pedro (2003), "A construção social de identidades de escola", Trajectos, 2, Lisboa, ISCTE/Editorial Notícias, pp. 13-22.

Abrantes, Pedro, e Maria Luísa Quaresma (2013), "Schools for the elite, schools for the poor: the same educational system, contrasting socialization environments", Italian Journal of Sociology of Education, 5 (2), pp. 133-159. 
Adick, Christel (2005), “Transnationalisierung als Herausforderung für die international und interkulturell vergleichende Erziehungswissenschaft", Tertium Comparationis. Journal für International und Interkulturell Vergleichende Erziehungswissenschaft, 11 (2), pp. 243-269.

Ball, Stephen J., e Dimitra Nikita (2014), “The global middle class and school choice: a cosmopolitan sociology", Zeitschrift für Erziehungswissenschaft, 17 (3), pp. 81-93.

Beck, Ulrich (2004), Der kosmopolitische Blick oder: Krieg ist Frieden, Frankfurt, a.M., Suhrkamp.

Beck, Ulrich (2007), “The cosmopolitan condition: why methodological nationalism fails", Theory, Culture and Society, 24 (7-8), pp. 286-290.

Bohnsack, Ralf, Nicolle Pfaff, e Wivian Weller (orgs.) (2010), Qualitative Analysis and Documentary Method in International Educational Research, Opladen e Farmington Hills, Barbara Budrich.

Boltanski, Luc, e Eve Chiapello (1999), Le Nouvel Esprit du Capitalisme, Paris, Gallimard.

Bourdieu, Pierre (1972), Esquisse d'Une Théorie de la Pratique, Genebra, Droz.

Bourdieu, Pierre (1979), La Distinction. Critique Sociale du Jugement, Paris, Les Editions de Minuit.

Bourdieu, Pierre (1989), La Noblesse d'Etat, Paris, Les Editions de Minuit.

Brooks, Rachel, e Johanna Waters (2011), Student Mobilities, Migration and the Internationalization of Higher Education, Basingstoke, Palgrave Macmillan.

Cairns, David, Valentina Cuzzocrea, Daniel Briggs, e Luísa Veloso (2017), The Consequences of Mobility. Reflexivity, Social Inequality and the Reproduction of Precariousness in Highly Qualified Migration, Basingstoke, Palgrave Macmillan.

Castells, Manuel (2000), The Rise of the Network Society, Oxford, Blackwell (2. edição).

Costa, António Firmino da (2012), Desigualdades Sociais Contemporâneas, Lisboa, Editora Mundos Sociais.

Deppe, Ulrike, Claire Maxwell, Heinz-Hermann Krüger, e Werner Helsper (2018), “Elite education and internationalisation - from the the early years to higher education: an introduction", em Claire Maxwell, Ulrike Deppe, Heinz-Hermann Krüger e Werner Helsper (orgs.), Elite Education and Internationalisation. From the Early Years to Higher Education, Basingstoke, Palgrave Macmillan, pp. 1-22.

Draelants, Hugues, e Xavier Dumay (2011), L'Identité des Etablissements Scolaires, Paris, PUF.

Favell, Adrian (2008), Eurostars and Eurocities. Free Movement and Mobility in an Integrating Europe, Malden, Oxford e Carlton, Blackwell Publishing.

Hartmann, Michael (2004), Elitesoziologie: Eine Einführung, Frankfurt, a.M., e Nova Iorque, Campus Verlag.

Hartmann, Michael (2011), “Die transnationale Klasse - Mythos oder Realität”, em Cornelia Koppetsch (org.), Nachrichten aus den Innenwelten des Kapitalismus. Zur Transformation moderner Subjektivität, Wiesbaden, VS Verlag für Sozialwissenschaften, pp. 79-98.

Hayden, Mary (2011), "Transnational spaces of education: the growth of the international school sector", Globalisation, Societies and Education, 9 (2), pp. 211-224.

Keßler, Catharina, Heinz-Hermann Krüger, Anne Schippling, e Ariane Otto (2015), “Envisioning world citizens? Self-presentations of an international school in 
Germany and related orientations of its pupils", Journal of Research in International Education, 14 (2), pp. 114-126.

Lauder, Hugh (2015), “International schools, education and globalization: towards a research agenda", em Mary Hayden, Jack Levy e Jeff Thompson (orgs.), The Sage Handbook of Research in International Education, Londres, Sage Publications, pp. 172-182 (2. ․ edição).

Louçã, Francisco, João Teixeira Lopes, e Jorge Costa (2014), Os Burgueses, Lisboa, Bertrand Editora.

Macedo, Eunice (2009), Cidadania em Confronto. Educação de Jovens Elites em Tempo de Globalização, Porto, CIIE \& Livpsic.

Macedo, Eunice, e Helena C. Araújo (2016), “Can geographies of privilege and oppression combine? Elite education in Northern Portugal", em Aaron Koh e Jane Kenway (orgs.), Elite Schools. Multiple Geographies of Privilege, Londres, Routledge, pp. 157-170.

Maxwell, Claire, e Peter Aggleton (orgs.) (2016), Elite Education. International Perspectives, Abington e Nova Iorque, Routledge.

Maxwell, Claire, Ulrike Deppe, Heinz-Hermann Krüger, e Werner Helsper (orgs.) (2018), Elite Education and Internationalisation. From the Early Years to Higher Education, Basingstoke, Palgrave Macmillan.

Mills, Charles Wright (1956), The Power Elite, Nova Iorque, Oxford University Press.

Naudet, Jules (2012), Entrer dans l'Elite. Parcours de Réussite en France, aux Etats-Unis et en Inde, Paris, PUF.

Nohl, Arnd-Michael (2006), Interview und dokumentarische Methode, Wiesbaden, Springer VS.

Pinçon, Michel, e Monique Pinçon-Charlot (2007), Sociologie de la Bourgeoisie, Paris, La Découverte.

Power, Sally, Phillip Brown, Annabelle Allouch, e Gerbrand Tholen (2013), “Self, career and nationhood: the contrasting aspirations of British and French elite graduates", British Journal of Sociology, 64 (4), pp. 578-596.

Quaresma, Maria Luísa (2014), Entre o Herdado, o Vivido e o Projetado. Estudo de Caso sobre o Sucesso Educativo em Dois Colégios Privados Frequentados pelas Classes Dominantes, Porto, Edições Afrontamento.

Reay, Diane (1998), “'Always knowing' and 'never being sure': familial and institutional habituses and higher education choice", Journal of Education Policy, 13 (4), pp. 519-529.

Resnik, Julia (2016), “Elite education systems in the emerging financial powers: commentary", em Claire Maxwell e Peter Aggleton (orgs.), Elite Education. International Perspectives, Abington e Nova Iorque, Routledge, pp. 186-191.

Roman, Leslie G. (2003), “Education and the contested meanings of 'global citizenship' ", Journal of Educational Change, 4 (3), pp. 269-293.

Santos, Susana (2018), "Becoming a lawyer in a large law firm: the idea of the unstoppable worker", Professions \& Professionalism, 8 (3), https://doi.org/10.7577/pp.2285

Sassen, Saskia (2005), "New global classes: implications for politics”, em Anthony Giddens e Patrick Diamond (orgs.), The New Egalitarianism, Cambridge, Polity Press, pp. 143-153. 
Schippling, Anne (2018a), "Institutional habitus of French elite colleges in the context of internationalisation: an in-depth look at the Ecoles normales supérieures", em Claire Maxwell, Ulrike Deppe, Heinz-Hermann Krüger e Werner Helsper (orgs.), Elite Education and Internationalisation. From the Early Years to Higher Education, Basingstoke, Palgrave Macmillan, pp. 279-296.

Schippling, Anne (2018b), “Researching international schools: challenges for comparative educational research", Revista Lusófona de Educação, 41 (41), pp. 193-204.

Schippling, Anne, e Pedro Abrantes (2018), "Para uma visão panorâmica do campo das escolas internacionais na Grande Lisboa", Educação, Sociedade E Culturas, 52, pp. 7-27.

Sklair, Leslie (2001), The Transnational Capitalist Class, Oxford, Wiley-Blackwell Publishing.

Vieira, Maria Manuel (2003), Educar Herdeiros. Práticas Educativas da Classe Dominante Lisboeta nas Últimas Décadas, Lisboa, Fundação Calouste Gulbenkian.

Wagner, Anne-Catherine (2007), Les Classes Sociales dans la Mondialisation, Paris, La Découverte.

Waldow, Florian (2018), “Commentary to Part III: why is 'being international' so attractive? 'Being international' is a source of legitimacy and distinction", em Claire Maxwell, Ulrike Deppe, Heinz-Hermann Krüger e Werner Helsper (orgs.), Elite Education and Internationalisation. From the Early Years to Higher Education, Basingstoke, Palgrave Macmillan, pp. 247-253.

Anne Schippling. Investigadora no Centro de Investigação e Estudos de Sociologia (CIES-Iscte), Iscte - Instituto Universitário de Lisboa, Lisboa, Portugal e professora convidada da FernUniversität in Hagen, Alemanha.

E-mail: anne.schippling@iscte-iul.pt

Pedro Abrantes. Professor da Universidade Aberta e investigador no Centro de Investigação e Estudos de Sociologia (CIES-Iscte), Iscte - Instituto Universitário de Lisboa, Lisboa, Portugal. E-mail: pedro.abrantes@iscte-iul.pt

João Teixeira Lopes. Professor catedrático do Departamento de Sociologia da FLUP e investigador do IS-UP, Porto, Portugal. E-mail: jmteixeiralopes@gmail.com

Receção: 06 de dezembro de 2018 Aprovação: 03 de maio de 2019 